\title{
DOES TRANSACTION COST THEORY EXPLAIN INFORMATION SYSTEMS OUTSOURCING IN THE U.S GOVERNMENT?: AN EMPIRICAL TEST
}

\author{
Yong-Mi Kim* and Hee Joon Song**
}

\begin{abstract}
The explanatory power of transaction cost theory has been demonstrated in the management of non-information system(IS) arenas. This theory assumes that human beings display bounded rationality and opportunistic behavior, which is then passed to the organization and market. Therefore, such behavior assumed by transaction cost theory leads to organizational and market failures downstream. In order to reduce the level of these failures, the theory suggests insourcing or outsourcing for certain goods or services.

Since this theory has been found to explain managerial decisions in non-IS areas, this research examines whether the theory holds the same explanatory power in the IS arena. Research results showed that the theory does not appear to hold in the area to IS management. The resource-based perspective may provide a more appropriate alternative in understanding decisionmaking in regards to IS outsourcing within city governments.
\end{abstract}

\section{INTRODUCTION}

There are explanations for sourcing various governmental functions including transaction cost theory, diffusion of technology and learning theory, organizational and bureaucratic factors, and so forth. The explanatory power of transaction cost theory, developed by Williamson (1975, 1985, 1996), has been tested recently by many scholars in various ways(Ferris and Graddy, 1988, 1991; Pisano, 1990; Anderson, 1985; Walker and Weber, 1984). According to this theory, certain goods and/or services should be either insourced or outsourced in ways of reducing transaction costs, which are derived from market and organizational failures.

This theory holds a strong explanatory power in non-IS arenas. When it comes to the IS field, the question is whether this theory is still applicable to the functions affected by the rapidly changing

* Adjunct Professor, Florida Atlantic University.

** Professor, Ewha Women's University. environments (human knowledge and equipment). Saunders et al. (1997), Lacity and Willcocks (1995), and Grover and Teng (1993) argued that IS outsourcing is very different from non-IS outsourcing and consequently, transaction cost theory cannot provide a managerial guideline. However, some scholars (Globerman and Vining, 1996; Alpar and Saharia, 1995) in the IS area, believe that transaction cost theory is applicable to the IS area. The former group of researchers performed empirical tests in order to argue the applicability of the theory, whereas the latter group did not conduct surveys. This paper examines the applicability of transaction cost theory. Empirical evidence from IS outsourcing in city governments is used to assess the applicability of transaction cost theory to IS outsourcing.

\section{TRANSACTION COST THEORY AND HYPOTHESES}

Transaction cost theory is based upon an 
cconomic framework which explains the rcasons why firms seek to outsource or insource certain goods and services. Coase (1937), Williamson $(1975,1985,1986)$, and Walker and Weber (1984) argued that a transaction is governed either by the market or by the hierarchy of an organization. Market mechanisms, such as price movement and direct production, are coordinated through a series of exchanges in the market, whereas hierarchical control is coordinated by a decision-maker within an organization. Both mechanisms create certain transaction costs (Coase, 1937). He argued that a firm would retain and produce certain goods or services within the firm unless the cost of production within the firm exceeded the cost for purchasing the final product from outside. Therefore, transaction costs eventually determine the size of a firm. Essential elements of transaction cost theory (i.e., asset specific functions, information confidentiality, opportunism, frequency, and uncertainty) are discussed below.

\section{Asset Specific Functions}

Asset specificity refers to functions that are designed specifically to meet an organization's needs. Attributed to most of the transaction cost, asset specificity is composed of physical and human factors. Human asset specificity is related to the specialized knowledge to complete a project. It is a "know-how" advantage. This asset can be obtained by experience or by doing something repeatedly (Williamson, 1979). Facility asset specificity is related to a project that is designed for a specific company or purpose. Williamson (1975, 1985, 1996) assumed human being's bounded rationality and opportunistic behavior. Those assumptions are involved with high transaction costs, especially when bounded rationality is paired with uncertainty/complexity, and opportunism in conjunction with small number exchange relations.

Given these assumptions, if the project is unique to a company and is highly complicated, collecting information concerning the project is not realistic due to a human being's bounded rationality, and therefore, insourcing is desirable in this case (Williamson, 1985). The reason is that when a function is specific to an organization (asset specific function), the outsource-seeking company may not have sufficient information about the project, whereas the vendor may have more information because the vendor is specialized in that area. This is where information asymmetry arises between the two parties. This creates room for the vendor to behave opportunistically, which leads to high transaction costs. Williamson $(1975,1985,1996)$ called it "market failure." If providers are numerous in the market, information asymmetry will be attenuated. However, since the project is designed specifically for a firm, we cannot expect many vendors for that function. Therefore, a firm should manage the function internally so as to pre-empt the internalization of market failures.

IS and non-IS activities are significantly different. Costs associated with IS projects are difficult to predict because of rapid changes in hardware costs and software production technologies. Also, massive sunk cost in both computing and human capital is a huge expenditure, yet both the facility and the human knowledge become obsolete quickly (Andersen and Dawes, 1991).

Grover et al. (1993, 1996) found that asset specific functions are outsourced to gain access to cuttingedge technology. Technical benefits from outside vendors can be obtained by overcoming limited facilitics or lack of personnel within the organization (Grover et al., 1993, 1996). This argument challenges the applicability of transaction cost theory to the IS outsourcing decision. Saunders et al. (1997) validated Grover et al.'s (1993, 1996) argument by finding that $24 \%$ of companies primarily sought IS outsourcing for technological considerations, $18 \%$ for cost savings, $15 \%$ for strategic considerations, and $9 \%$ for human resource 
considerations. This empirical research revealed that companies outsourced their asset-specific IS functions in order to gain access to leading edge technology. They further contended that in the case of outsourcing for asset specific functions, the outsource-seeking company should make a tight contract to prevent opportunistic behavior on the part of the vendor, such as leaking secrets of the project to a third party.

Similarly, Lacity and Hirschheim (1993) confirmed that $50 \%$ of outsource-seeking companies outsourced their IS functions including asset specific functions. In similar research, Altinkemer et al. (1994) found that 12 of 62 firms (19\%) outsourced their entire IS functions including asset specific functions. This reasoning leads to hypothesis 1 .

\begin{abstract}
Hypothesis I: If IS functions require a unique technology, then city governments are likely to allocate a higher percentage of their IS budgets to outsourcing those functions.
\end{abstract}

\section{Confidential Information}

In the non-IS area, previous researchers (Anderson, 1985; Pisano, 1990) categorized confidential information within the boundary of asset specificity. This classification was made because this information usually belonged to a company's core function. In order to protect secret functions of the company, confidential information should be retained within the hierarchy. Pisano's (1990) research supported this argument that confidential information should be managed internally. A product associated with confidential information, measured by the possibility of leaking "knowhow" to competitors, supported the insourcing decision in the non-IS area (Pisano, 1990). Another study in the non-IS area, which concerned confidential information, was conducted by Anderson (1985). His measure of confidential information, specifically the "need to know accounts and importance of key accounts," supported the theory that a firm would incorporate a confidential function within the organization. The author pointed out that a leak of the confidential information to outside competitors could be damaging to the organization. In the city government, confidential information is concerned mainly with citizens' privacy. Sunshine laws, however, require a significant portion of information to be made available to the citizenry. Florida was the first state to adopt the laws. By 1977, all the states had passed sunshine laws, varying widely from state to state in disclosing information. It should be noted that policemen and firefighters are exempted under this law. Even though there are some variations among cities, public access to city government information is basically covered by sunshine laws.

Hypothesis 2: Concerns for confidentiality and privacy are less likely to be related to IS outsourcing expenditure in the city government.

\section{Opportunism}

According to transaction cost theory, opportunistic behavior is the biggest obstacle to the outsourcing of asset specific functions. Williamson (1985) defined opportunism as the incomplete or distorted disclosure of information, especially to calculated efforts to mislead, distort, disguise, obfuscate, otherwise confuse(p. 47). In the IS area, the vendors are well informed about the development of IS, whereas IS managers in the city government may not be so well informed. Williamson $(1975,1985,1996)$ argued that information asymmetry, which will result in opportunistic behavior, is usually derived from a complex contract with a small number of vendors. Lacity and Willcocks (1995) contend that a small number of suppliers is the norm rather than the exception within the IS field due to massive sunk costs and high switching costs.

Globerman and Vining (1996) further developed the idea that at the post-contract stage, low con- 
testability increases the risks of opportunism (and associated costs). This occurs for two reasons: first, a provider cannot be quickly replaced; second, there is a heightened risk of contract breach externalities. This risk is especially relevant when the vendor provides services that are related to a network of some kind. For example, a firm carrying out government computer operations may threaten to withdraw service in a way that jeopardizes the payment of all government paychecks, welfare checks, and unemployment insurance checks. For this reason, the U.S. Office of Management and Budget Circular A-76 explicitly precludes outsourcing of functions that are critical to the U.S. national defense. Similarly, the Department of Justice's law enforcement activities have been explicitly exempted from outsourcing requirements. Situations where governments fear contract breach externalities are often defined as strategic systems.

Chalos (1996) cited a U.S. Department of Commerce report that showed 20 firms out of a total of $2,000(1 \%)$ earned half of the $\$ 27$ billion in revenues for U.S. information systems in 1990. He then concluded that the data processing services provided by the IS vendors could be unique and asset-specific, leading the buyer to a bargaining disadvantage. If IS vendors have unique access to proprietary or market information and do not share the information with the city government (information asymmetry), the city government risks increasingly high costs with low quality services.

Other scholars and practitioners also have pointed out the possibility of opportunistic behaviour from vendors (Lacity and Hirschheim, 1993, 1995a, 1995b; Lacity et al., 1996; Quinn, 1995). The main concerns involve service quality and unreasonable charges due to changes in business or technology. Collines and Millen's (1995) illustrated that the most frequently cited IS outsourcing reservations were the loss of control of IS $(56 \%)$, loss of IS strategic planning capability (17\%), and cost $(42 \%)$.
This argument leads to hypothesis 3 .

Hypothesis 3: If city governments are concerned about problems of low service quality, then they are less likely to allocate IS outsourcing expenditure.

\section{Market Competition (asset non-specificity)}

Market competition is another important reason for outsourcing. Market competition is defined as the availability of reputable and trustworthy external IS service providers in the market (Walker and Weber, 1984). When the market is competitive, relevant information is summarized by the price system. In this case, outsourcing is desirable because a firm can take economic advantage and gain high quality services from outside vendors. This is because when asset is not specific to an organization, many organizations use the same function, and consequently, many vendors are available in the market to perform this function (e.g., street lighting, garbage collection, etc). In turn, this forces the vendors to reduce production costs derived from economies of scale, minimizing transaction costs in the market. Also, an outsourceseeking organization can obtain information concerning the contract clauses, which will reduce vendors' opportunistic behavior.

Another benefit of supplier competition is that outsource-sccking companies preserve their original service levels from alternative providers. According to Pisano (1990), market competition among pharmaceutical companies better preserved the value of its original $R \& D$ investment in the event that the agreement with the initial contractor was terminated. Pisano (1990) also claimed that opportunism would likely create a hazardous transaction in the market in a small number of bidding or competing firms.

Ferris and Graddy (1988) conducted an empirical test to examine the relationship between the number of service providers and production cost in the public sector. The researchers found that the 
main reason for outsourcing, and perhaps this is even true for the IS outsourcing, was cost savings: if the competition among suppliers is intense, the service delivery costs tend to be low.

For this reason, outsourcing is advantageous when competition exists among suppliers (Ferris, 1986; Ferris and Graddy, 1986, 1988, 1991; Globerman and Vining, 1996; Miranda and Andersen, 1996; Prager, 1994; Williamson, 1979, 1986). This argument leads to hypothesis 4 .

Hypothesis 4: The greater the levels of market competitiveness (more vendors in the market), the more likely it is that the city government will outsource those IS functions.

\section{Frequency}

Frequent use of a function is also another important determinant when trying to decide whether to outsource. If a city government uses an IS function frequently, the city government may insource the function because the investment costs can be recovered by using the function repeatedly. If an organization uses an IS function temporarily, however, the economic advantages achieved by incorporating the function could not be appreciated. Demand for a certain IS function may be more sporadic than demand for other IS functions in the city government. For instance, the workload for systems development tends to vary. In the beginning of the project, the workload is heavy. After the project is set up, city governments need to maintain the IS function. The workload for systems support remains relatively constant. Accordingly, the tasks of programmers, systems analysts, systems engineers, and consultants are more likely to be outsourced than those of the more stable and predictable positions, like database administrators, network administrators, or systems programmers (Slaughter and Ang, 1996). If an IS function was used sporadically, the IS function was a good candidate for outsourcing. Their empirical test supported this argument. This reasoning generates Hypothesis 5.

Hypothesis 5: If a city government uses an IS function temporarily, then the city government will be more likely to outsource the function.

\section{Uncertainty}

Transaction cost theory suggests that when the situation is uncertain, firms will insource the function affected by uncertain circumstances in order to respond in a timely manner. Contrary to the theory, Essels' (1981a and 1981b) research findings did not support the theory. The site of the research was a construction company, which operated under the uncertainty of a labor supply and the demand for construction work. They found that in the construction industry, construction companies submitted a bid price to clients who usually requested asset specific construction. Since construction companies could not predict the demand for work, they had to go through a repeated hiring and firing process. For this reason, the construction companies subcontracted with labor suppliers, forcing these subcontractors to absorb the uncertainty faced by the construction industry. Outsourcing in that case is beneficial for the construction company.

In the IS area, Walker and Weber (1984) claimed that the problems of evaluating supplier performance under high uncertainty and of suffering potential supplier opportunism under high asset specificity would be both reduced when managers handled the function internally. Their research on technological uncertainty, however, did not confirm the theory that the company should manage the function internally. Technological uncertainty is measured by frequency of expected changes in specifications and the probability of future technological improvements of the component. Uncertain development of IS knowledge and facilities is one of the critical barriers in undertaking the perfor- 
mance of IS activities internally. In addition, it especially is difficult to carry out some of these IS functions internally in the face of rapidly developing technology, knowledge, and the quickly declining costs of IS facilities. These factors present barriers for the city government to become equipped with IS personnel and facilities internally. Balakrishnam and Wernerfelt (1986) argued that organizations outsourced due to the difficulty in keeping up the skills of depreciated and stagnated IS experts. In addition, Ang (1993) claimed that when IS development proved to be uncertain, organizations usually spread their risks and costs to outside vendors by outsourcing.

Indeed, as noted by Balakrishnan and Wernerfelt (1986), organizations would shift their IS functions to external service providers in order to reduce the financial burden. This outcome resulted from depreciating or stagnated IS professionals' skill. Recognizing the difficulty in keeping IS functions in the organization under the situation of technological uncertainty, Ang (1993: 39) argued "as technological uncertainty increases, internal economies of specialization deteriorate relative to the external economies of specialization of service providers, since service providers can distribute innovation risks over a larger pool of clientele." In summary, uncertain development of IS drives firms to outsource, leading to Hypothesis 6 .

Hypothesis 6: If city governments are concerned about the potential obsolescence of their IS knowledge and equipment, then they are more likely to outsource their IS functions.

\section{Internal Transaction Costs}

Transactional arguments in favor of vertical integration should confront this dilemma because opportunism and bounded rationality also exist within the organization. Bounded rationality gives rise to finite spans of control. For this reason, an organization becomes taller as the size of the organization increases, and it will eventually create communication distortion (Williamson, 1975). On the other hand, internal opportunism takes the form of subgoal pursuit at the expense of organizational interest. Such efforts generally involve distorting communications in a strategic manner (Williamson, 1975). Williamson (1975) termed it "organizational failure." When the failure ensues, the manager cannot process all information due to the human being's bounded rationality. Additionally, managers try to increase the size of their unit while sacrificing organizational efficiency. Thus, the theory suggests that if a function is not specific to an organization, the company is better off by outsourcing the function in order to reduce the size of the firm.

For the internal transaction costs, bureaucratic environments are mainly responsible for the costs incurred in the public organization. According to Bretschneider (1990), the IS manager in public organizations may be dealing with outside boundaries of the organization when initiating IS planning. High levels of interdependency lead to higher levels of uncertainty and lower levels of control over the environment by the IS manager. This condition forces planning to function more as a vehicle for managing interorganizational linkages than coordination of effort within the organization (Bretschneider, 1990). The CEO in private organizations emphasizes internal coordination of the organization and develops IS plans based on the boundaries of the organization.

Procedural delay is another factor which prevents the efficient management of IS in the public organization. Technology develops exponentially and requires a timely response to the rapidly changing IS environment. Since expenditure approval in the public organization generally took an average of two to four weeks (Bretschneider, 1990), the IS manager may not be able to cope with the demand for IS services on time. Therefore, organizations compare internal and external transaction costs as 
part of their decision to outsource or insource. This argument leads to Hypotheses 7-1 and 7-2.

Hypothesis 7-1: The longer the time required to secure IS outsourcing expenditure, the less likely it is that the city government will allocate the city budget to IS outsourcing expenditure.

Hypothesis 7-2: The greater the number of hierarchical levels involved in order to secure IS outsourcing expenditure, the less likely it is that the city government will allocate the city budget to IS outsourcing expenditure.

\section{Type of City Government}

The type of city government is an important factor in explaining IS outsourcing decisions. As an outgrowth of the Progressive era, the councilmanager type of local government gave rise to a vision of administrative efficiency and technical expertise in the city government. Scientific management and administration, the underpinnings of this belief, are related aspects of a general movement of the scientific method and the spirit of society's concerns. Economy, efficiency, and other quasiscientific concepts are more treasured than other values, such as one's relationship with interest groups. With this spirit, the council-manager type of city government tends to focus on internal efficiency, such as management of city government under constrained budgets. On the other hand, the mayor-council type of city government is more likely to be concerned with the citizens' needs and relationships with them because mayor and council members are elected officials.

In this context, Ferris and Graddy (1988, 1991) found that the manager-council type of local government was more likely to adopt outsourcing for service delivery than its counterpart because outsourcing is a good tool to reduce costs. For example, in 1975 San Francisco outsourced its garbage collection and the citizens paid $\$ 40$ a year for private service, whereas New Yorkers in two comparable neighborhoods were paying $\$ 297$ a year to their municipal collection. Also, Little Rock, Arkansas outsourced its city hall janitorial services and saved 50\% in costs in 1977. Cypress, California, saved 20\%, and Phoenix, Arizona, saved $57 \%$ in janitorial services. Orange County, California, reduced costs by approximately $33 \%$ by outsourcing its data processing (Linowes, 1988). These findings lead to hypothesis 8 .

Hypothesis 8: The council-manager type of city government will be more likely to outsource than the mayor-council type of city government.

\section{RESEARCH METHOD}

To test the explanatory power of transaction cost theory to the IS outsourcing decision, a questionnaire was sent to 800 randomly selected American cities in 1998. In order to ensure that similar numbers of samples were drafted from each governmental type, 400 samples were randomly selected. Then the questionnaire was directed to the IS manager or the financial manager if a city government did not have an IS department. The list of cities and types of city governments was obtained from The Municipal Year Book of 1998. The names and addresses of these managers were collected from Carroll's Municipal Directory of 1998.

The response rate was $29 \%$ (232 responses). Although this response rate is favorable for analysis, more importantly, we should examine the possibility of bias between the responding and non-responding city governments (Babbie, 1986). For this test, we used total population and total city expenditure. We randomly selected 100 cities from non-responding cities and compared their total city expenditure and city populations. Results of the t-test showed no differences between the nonrespondents and respondents. This finding suggests that the findings of the total population can be 
generalized.

Among the 232 responses, 28 questionnaires were returned with unusable responses, indicating that the city government policy did not allow responses to survey questionnaires. Of the 204 responses that were usable, some respondents did not answer some of questions, especially those corresponding to the dependent variable and the internal transaction cost variables. In such a case, one should test whether the two groups--responses with all answers and responses with missing variables-- are different. This test result revealed that the two groups were not different. Hair et al. (1995) suggested that in such a case, the analyst could use any kind of remedy.

Data were derived heavily from the questionnaire, which contains multiple items to measure the transaction cost theory. To test the theory, regression analysis was used since the purpose of the analysis was to test whether city governments outsource IS based upon the guidelines suggested by transaction cost theory. For the dependent variable, IS outsourcing expenditure as a percentage of total IS expenditure was used to express a percentage of the organization's total IS budget (Teng et al., 1995; Loh and Venkatraman, 1992). In order to determine the applicability of transaction cost theory to the IS management, seven main areas were selected: asset specificity, confidential information, market competition, uncertainty, frequency, internal transaction cost, and external transaction cost theory. For asset specificity, human and facility asset specificity were tested. The assumption test, however, showed that the two variables revealed a high level of multicollinearity. Accordingly, one variable should be removed from the analysis. For this analysis the human asset specificity variable was used. Confidential information was measured by four factors: we do not outsource (1) if an IS function must be kept confidential; (2) if an IS function involves a citizen's privacy; (3) if it is related to an internal organizational secret; and (4) if it is related to an internal employee's privacy. These four variables also showed a high level of multicollinearity, and thus, the second variable, "if an IS function involves a citizen's privacy," was selected. For the internal transaction cost theory test, the amount of time a city government should spend or the number of hierarchical levels it needs to go through for the outsourcing approval were considered. For the external transaction cost theory, opportunism was used. Two variables, low service quality and unreasonable charges, showed a high multicollinearity, leading to the use of low service quality in this analysis. These items were measured on a seven-point Likert and numerical scales. The definition and operationalization of each measure are described in detail in Table 1.

\section{RESEARCH FINDINGS}

This section discusses the research findings. The descriptive analysis of variables is reported in Table 2, and the results of the regression analysis are provided in the following table (Table 3 ).

\section{Descriptive Analysis of Variables}

The descriptive analysis of the variables in the analysis is provided in Table 2. The highest mean is shown in the low service quality question, which means that city IS administrators are concerned about the quality of service when the IS functions are outsourced. The second highest mean appears in the area of technology specific factors. The respondents replied that they tended to outsource when an IS function required unique technology. As expected, the lowest mean appears in the variable, "Citizen's privacy."

\section{Analysis of IS Outsourcing Expenditure}

Table 3 shows the regression analysis of IS outsourcing expenditure as a percentage of the total 
Table 1. Operationalization of the Variables in the Analysis

\begin{tabular}{|c|c|}
\hline Variables & Measurement \\
\hline Unique technology & We outsource when an IS function requires a unique technology* \\
\hline Citizen's privacy & We do not outsource if an IS function involves a citizen's privacy* \\
\hline Low service quality & We are concerned about the quality of the service when outsourced ${ }^{*}$ \\
\hline Market competition & $\begin{array}{l}\text { We outsource when numerous service providers exist for an IS function, } \\
\text { which makes outsourcing cheaper than in-house management* }\end{array}$ \\
\hline Cost reduction & $\begin{array}{l}\text { We think that IS outsourcing is critical to reduce overall cost of } \\
\text { information systems services }\end{array}$ \\
\hline Infrequent use & We outsource an IS function if we use the function infrequency ${ }^{*}$ \\
\hline Uncertainty & We outsource when we can reduce the risk of technological obsolescence* \\
\hline $\begin{array}{l}\text { Period of time for securing outsourcing } \\
\text { approval }\end{array}$ & The numbers of days for securing IS outsourcing expenditure. \\
\hline Levels of hierarchy & $\begin{array}{l}\text { Levels of the hierarchy between the IS administrator and the final } \\
\text { decision-maker for IS outsourcing. }\end{array}$ \\
\hline Governmental type & $0=$ council-manager type $1=$ mayor-council type. \\
\hline
\end{tabular}

* Variables are measured by a 7-point Likert scale: 1 being strongly disagree, 7 being strongly agree.

IS outsourcing expenditure: $\alpha+\beta 1$ (unique technology) $\beta 2$ (citizen's privacy)

$-\beta 3$ (low service quality) $+\beta 4$ (market competition)

$+\beta 5$ (cost reduction) $+\beta 6$ (infrequent use)

$+\beta 7$ (uncertainty) - $\beta 8$ (internal transaction cost)

$+\beta 9$ (governmental type)

Table 2. Descriptive Statistics of the Variables in the Analysis

\begin{tabular}{|c|c|c|c|}
\hline Variables & $\mathrm{N}$ & Mean & Std. Dev \\
\hline Unique technology & 212 & 5.17 & 1.70 \\
\hline Citizen's privacy & 207 & 3.86 & 1.87 \\
\hline Low service quality & 213 & 6.04 & 1.16 \\
\hline Market competition & 206 & 4.63 & 1.61 \\
\hline Cost reduction & 214 & 4.13 & 1.75 \\
\hline Infrequent use & 210 & 4.94 & 1.65 \\
\hline Uncertainty & 204 & 4.64 & 1.48 \\
\hline Period of time for securing outsourcing approval & 176 & 17.33 & 12.97 \\
\hline Levels of hierarchy & 185 & 1.41 & 1.22 \\
\hline
\end{tabular}

* Variables are measured by a 7-point Likert scale: 1 being strongly disagree, 7 being strongly agree.

IS expenditures within the city government.

Overall, the findings reveal that IS management presents a challenge to the applicability of transaction cost theory: transaction cost theory is not an efficient managerial framework for evaluating the IS outsourcing decision in the city government. The first variable tests the asset specific IS function. As expected from Hypothesis 1, the city government outsourced this IS function in order to gain access to cutting-edge technology. In addition, the city government outsourced IS functions that were related to a citizen's privacy as expected from Hypothesis 2. Furthermore, the city IS managers did not appear to be concerned about the vendors' opportunistic behavior. According to the theory, when a function requires unique experience and is involved with company's confidential information, a company should insource in order to avoid 
Table 3. Regression Analysis of IS Outsourcing Expenditure as a Percentage of Total IS Expenditure

\begin{tabular}{l|ccc}
\hline \multicolumn{1}{c|}{ Variables } & B & SE B & T-value \\
\hline \hline Unique technology & 4.56 & 1.63 & $2.807^{* * *}$ \\
Citizen's privacy & -5.13 & 1.18 & $-4.370^{* * *}$ \\
Low service quality & -.97 & 1.64 & -0.591 \\
Market competition & -4.02 & 2.00 & $-2.012^{* *}$ \\
Reduction of cost & -1.52 & 1.77 & -0.855 \\
Obsolescencc of IS facilitics or knowlcdge & 2.15 & 2.15 & 1.002 \\
Infrequent use & 1.68 & 1.25 & 1.349 \\
Uncertainty & -0.08 & 1.76 & -.047 \\
Period of time for securing outsourcing approval & -0.13 & 0.11 & -1.169 \\
Levels of hierarchy & -2.86 & 1.15 & $-2.482^{* *}$ \\
Governmental type & -16.93 & 4.61 & $-3.671^{* * *}$ \\
\hline
\end{tabular}

R Square: 0.2993

$\begin{array}{lll}F: & 5.36^{* * *} & N\end{array}$

vendors' opportunistic behaviors such as unreasonable charges and/or low service quality. Contrary to the theory, however, city governments outsourced IS when they perceived that gaining access to unique experience was important. As discussed, confidential information is vulnerable to vendors' opportunistic behavior. Sunshine laws require a significant portion of information to be made available to the citizenry, and accordingly, confidential information is not an obstacle to IS outsourcing in the city government. Interestingly, although asset specific functions were outsourced, city IS administrators were not concerned about the low service quality.

The decision to outsource also is influenced by internal transaction costs. For instance, if the period required to secure IS outsourcing is too long and IS managers need to go through several levels of hierarchy, then city governments may not react quickly to changing IS environments. Furthermore, as the levels of hierarchy increase, the manager may be less likely to recognize the importance of IS outsourcing. There is strong evidence in the research findings to indicate that if IS managers had to go through many hierarchical levels, city IS managers were less likely to seek out
IS outsourcing. This is significant at $95 \%$. Even though the statistical significance level is low, this research indicates that the longer the period required to secure approval for IS outsourcing, the less likely it will be that city governments will outsource. This result implies that internal transaction costs served as an obstacle for IS outsourcing in the city government, supporting Hypothesis 3 .

Unexpectedly, the test of market competition (asset non-specificity) does not support the theory. According to transaction cost theory and Hypothesis 4, when the market is competitive, price signals summarize the relevant information, and consequently, vendors' opportunistic behavior or human being's bounded rationality will not threaten the contract. For this reason, outsourcing will provide benefit to the city government in saving production and transaction costs. Contrary to expectation, however, market competition and cost reduction variables are not important factors in the decision to outsource IS within the city government. In the IS area, a few vendors provide services due to massive sunk costs and the difficulty of keeping up with cutting-edge technology in terms of human and facility. According to face-to-face interviews and telephone interviews with city IS 
managers in Florida, one IS company provides $80 \%$ of IS products to the Florida city government. I acity and Willcocks (1995) contends that "in the area of information technology, high switching costs make the circumstances of a small number of suppliers the norm rather than the exception" ( $\mathrm{p}$. 228).

There has been a long debate with regard to efficiency of the two types of city governments. As an outgrowth of the Progressive Era, the council-manager type of city government is staffed with professionally trained managers who are similar to private sector CEOs and who are primarily concerned with the efficient management of the government. Also, some researchers (Ferris and Graddy, 1988, 1991) found that outsourcing provided cost saving. With this reasoning, numerous scholars in the non-IS arena reported that the council-manager type of city government is more likely to outsource than the mayor-council type of city government. The mayor-council type of city government, however, is more likely to outsource its IS functions. We surmise, therefore, that IS and non-IS outsourcings are significantly different. The main reason to outsource IS is not a cost reduction as shown in the analysis, but more importantly, gaining access to cutting-edge technology is a critical element in this decision. The council-manager type of city government tends to provide basic functions internally and outsource advanced functions, while the mayor-council type of city government is more likely to outsource all functions including basic functions (Kim, 2001).

The other variables that were used to test transaction cost theory did not show significance, which means that the theory is not efficient in explaining the activity of IS outsourcing decisions. According to the theory, in an effort to avert managerial concerns derived from obsolescence of IS facilities and IS knowledge, city governments outsource asset specific IS functions. Also, uncertain situations derive the organization to incorporate the function within the hierarchy in order to buffer uncertain supply of the goods and services. When tested, however, these variables do not support the theory.

These research findings are consistent with those of previous researchers (Saunders et al., 1997; Teng et al., 1995) who looked at transaction cost theory in the IS arena. Lacity and Willcocks (1995) reviewed 61 sourcing decisions made by 145 private organizations in the United States and United Kingdom, and found that $87.5 \%$ of information systems decisions is not explained by transaction cost theory. They argued that an adoption of theory from other areas should be critically examined when it is being applied to a new discipline.

\section{CONCLUSION: A SEARCH FOR AN ALTERNATIVE THEORY}

The empirical test of the applicability of transaction cost theory to IS management did not support the explanatory power as proven in non-IS areas because the management of IS is substantially different from the management of non-IS disciplines. Originally, the theory was designed to fix market failure and organizational failure. In non-IS areas, when a function involves specific activities and/or secrets to a firm, then a firm should insource the function, while other asset non-specific functions are outsourced. Contrary to the theory, city IS managers outsourced when a function required unique technology. Furthermore, market competition and cost reduction are not important factors when an outsourcing strategy is used.

Obviously, these findings challenge the applicability of transaction cost theory to IS management. Massive sunk cost in both computing and human capital is a huge expenditure, yet both the facility and the human knowledge become obsolete within a short period of time. And although a firm may be equipped with cutting-edge technology, costs asso- 
ciated with IS projects decline exponentially. As a result, organizations benefit from outsourcing asset specific functions.

Based on the findings of the empirical tests, we propose resource-based theory as an alternative theory to explain the management of IS. According to this theory, an organization tries to gain valuable, rare, and imperfectly imitable assets, which will enable the organization to gain a sustainable competitive advantage. When these resources are not available within the organization, then the organization will seek outside resources, which is the outsourcing option (Grant, 1991). Therefore, when the existing resources fall short of their expected performance, outsourcing can be a good strategy to fill the gap. Teng et al. (1995) empirically tested and confirmed this argument using the IS outsourcing decision. According to their findings, the higher the level of perceived discrepancy between the actual level of IS stock and the desired performance, the more likely it was that the firm would seek to outsource. Another research report from the small business development center program reported that "between $60 \%$ and $78 \%$ of individuals with entrepreneurial intent who received outsider assistance started a business as compared to $48 \%$ of the general population who indicated intent" (Chrisman, 1999). This finding implied that strategic use of rare resources from outside were an efficient leverage to accomplish organizational goals. In such a case, cost reduction is not an important factor for outsourcing as found in the analysis. Consequently, the resource-based approach could be an efficient means by which to explain the exercises of IS outsourcing within the city government.

It is interesting to examine whether transaction cost theory is a persuasive explanation for outsourcing government IS function in other countries such as Asian ones with a comparatively strong bureaucratic tradition.

\section{Bibliography}

Altinkemer, K., Chaturvedi, A. \& Gulati, R. 1994. Information Systems Outsourcing: Issues and Evidence. International Journal of Information Management. 14. 252 268 .

Alpar, P. \& Saharia, A. N. 1995. Outsourcing Information System Functions: An Organization Economics Perspective. Journal of Organizational Computing. 5(3): 197 217.

Andersen, D. F. \& Dawes, S. S. 1991. Government Information Management: A Primer and Casebook. New Jersey, Prentice-Hall.

Anderson, E., 1985. The Sales as Outside Agent or Employee: A Transaction Cost Analysis. 5(3): 234 254. August. Cambridge Massachusetts: Marketing Science Institute. .

Ang, S., 1993. The Etiology of Information Systems Outsourcing. Doctoral Dissertation. University of Minnesota.

Babbie, E. 1986. The Practice of Social Research: 4th ed. California. Wandsworth Publishing Co.

Balakrishnan, S. \& Wernerfelt , B. 1986. Technical Change, Competition and Vertical Integration. Strategic Management Journal. 7: 347 359.

Bretschneider, S. Sep./Oct. 1990. Management Information Systems in Public and Private Organizations: An Empirical Test. Public Administration Review. 536 -545.

Carroll's Municipal Directory, Oct.1997/Mar.1998, Washington D.C.: Carroll Publishing.

Chalos, P. 1995. Costing, Control, and Strategic Analysis in Outsourcing Decisions. Journal of Cost Management. 8 or http://www.elibrary. com/cgi-bin/hhweb/hhfetch? 41392206x0y444: Q016:D028.

Chrisman, James J. 1999. The Influence of OutsideGenerated Knowledge Resources on Venture Creation. Journal of Small Business Management. 37(4): $42 \sim 58$.

Coase, R. H. 1937. The Nature of The Firm. 
Economica. 386 405.

Collins, J. S. \& Millen, R. A. 1995. Information Systems Outsourcing by Large American Industrial Firms: Choices and Impacts. Information Resources Management Journal. 5 13.

Eccles, R. G. Sep. 1981a. Bureaucratic vs. Craft Administration: The Relationship of Market Structure to the Construction Firm. Administrative Science Quarterly. 26: 449 469. . 1981b. The Quasi-firm in the Construction Industry. Journal of Economic Behavior and Organization. 2: 335 357 .

Ferris, J. M. 1986. The Decision to Contract Out: An Empirical Analysis. Urban Affairs Quarterly. 22(2): 289 311. December.

Ferris, J. \& Graddy, E. 1991. Production Costs, Transaction Costs, and Local Government Contractor Choice. Economic Inquiry. 541 554. July.

Ferris, J. \& Graddy, E. 1988. Production Choices for Local Government Services. Journal of Urban Affairs. 10(3): $273-289$.

Ferris, J. M. \& Graddy, E. 1986. Contracting Out: For What? With Whom? Public Administration Review. $332 \sim 344$. Jul./Aug.

Globerman, S. \& Vining, A. R. 1996. A Framework For Evaluating The Government Contracting-out Decision With An Application To Information Technology. Public Administration Review. 56(6): 577 586.

Grant, R.M. 1991. The Resource-Based Theory Of Competitive Advantage: Implications For Strategy Formulation. California Management Review. 33(3): 114 135.

Grover, Varun, Myun Joong Cheon, and James T. C. Teng. 1993. The Effect Of Service Quality And Partnership On The Outsourcing Of Information Systems Functions. Journal of Management Information Systems. 12(4): 89 116. . 1996. The Effect of Service Quality And Partnership On The Outsourcing of Information Systems Functions. Journal of
Management Information Systems. 12(4):89 116. Spring.

Grover, V. \& Teng, J. T. C. 1993 . The Decision to Outsource Information Systems Functions. Journal of Systems Management. 34 38. November.

Hair, J. F., Anderson, R. E., Tatham, R. L. \& Black, W. C. 1995. Multivariate Data Analysis, fourth edition. New Jersey. Prentice Hall.

Kim, Yong-Mi. 2001. Do the council-manager and the mayor-council type of city government manage information systems (IS) differently; An empirical test. International Journal of Public Administration. 24(6). June.

Lacity, M. C. \& Hirschheim, R. 1993. The information systems outsourcing bandwagon. Sloan Management Review. $73 \sim 87$. Fall

Lacity C. Mary \& Willcocks, Leslie P. 1995. Interpreting information technology sourcing decisions from a transaction cost perspective: findings and critique. Accounting Management \& Information Technology. 5(3/4): 302 244.

Linowes, D. F. 1988. Privatization: Toward more Effective Government. Report of the president's commission on privatization.

Loh, L. \& Venkatraman, N. 1992. Diffusion of information technology outsourcing: Influence sources and the Kodak effect. Information Systems Research. 3(4): $334 \sim 358$.

Miranda, R. \& Andersen, K. 1994. Alternative service delivery in local government, 1982 1992. The Municipal Year Book. ICMA.

Pisano, G. P. 1990. The R\&D boundaries of the firm: An empirical analysis. Administrative Science Review. 35: 153 176.

Prager, J. 1994. Contracting out government services: Lessons from the private sector. Public Administration Review. 54(2): 176 184.

Quinn,F. 1995. Strategic outsourcing. http://ellibrary.com/cgibin/hhweb/hhweb/ hhfetch? 4139306x0y444:Q016:D073. 
Saunders, C., Gebelt, M \& Hu. Q. 1997. Achieving success in information systems outsourcing. California Management Review. 39(2): $63-79$.

Slaughter, S. \& Ang, S. 1996. Employment outsourcing in information systems. Communication of the $A C M .47 \sim 54$. July.

Walker, G. \& Weber, D. 1984. A transaction cost approach to make-buy decisions. Adminis trative Science Quarterly. 29: $373 \sim 391$.

Williamson, O. E. 1975. Markets and Hierarchies:
Analysis and Antitrust Implications New York: The Free Press. 1979. Transaction-cost economics: The governance of contractual relations. Journal of Law and Economics. 22(2): 233 261. 1985. Economic Organization: Firms, Markets and Policy Control. Washington Square: New York University Press. . 1996. The Mechanisms of Governance. New York: Oxford University Press. 